\title{
Effect of a polypropylene fibre on the behaviour of aerial lime- based mortars
}

\author{
A. Izaguirre ${ }^{a}$, J. Lanas ${ }^{b}$, J.I. Alvarez ${ }^{a, *}$ \\ ${ }^{a}$ Department of Chemistry and Soil Sciences, School of Sciences, University of Navarra, c/ Irunlarrea, 1, \\ 31008, Pamplona, Spain \\ ${ }^{b}$ CTH Navarra, Polígono Talluntxe II C/M, 10, 31192, Tajonar, Spain
}

$\mathbf{N}^{\mathbf{0}}$ of pages: 39

$\mathbf{N}^{0}$ of tables: 6

$\mathbf{N}^{\mathbf{0}}$ of figures: 8

Keywords: Admixture; Durability; Freezing and Thawing; Mechanical properties; Lime mortar; Polypropylene fibre

*Dr. Jose I. Alvarez Galindo

Dpto. de Química

Fac. de Ciencias

Universidad de Navarra

$\mathrm{C} /$ Irunlarrea, 1

31.080 Pamplona (Navarra)

Spain

Phone: 34948425600

Fax: 34948425649

E-mail: jalvarez@unav.es 


\title{
Effect of a polypropylene fibre on the behaviour of aerial lime- based mortars
}

\author{
${ }^{\mathrm{a}}$ A. Izaguirre, ${ }^{\mathrm{b}} \mathrm{J}$. Lanas, ${ }^{\mathrm{a} J . I . ~ A ́ l v a r e z ~}{ }^{*}$ \\ ${ }^{a}$ Department of Chemistry and Soil Sciences, School of Sciences, University of Navarra, c/ Irunlarrea, 1, \\ 31008, Pamplona, Spain \\ ${ }^{b}$ CTH Navarra, Polígono Talluntxe II C/M, 10, 31192, Tajonar, Spain
}

\begin{abstract}
A polypropylene fibre was added to lime-based mortars in order to check whether they were improved by this admixture. Different properties of lime-based mortars were evaluated: fresh state behaviour through water retention, air content and setting time; hardened state properties such as density, shrinkage, water absorption through capillarity, water vapour permeability, long-term flexural and compressive strengths, pore structure through mercury intrusion porosimetry, and durability assessed by means of freezing-thawing cycles. An improvement in some properties of aerial lime-based mortars - such as permeability, mechanical strengths, reduction in macroscopic cracks or durability in the face of freezing-thawing cycles - was achieved when fibre was added at a low dosage. When a larger amount of additive was used, only the reduction in cracks and the durability of the material were improved.
\end{abstract}

Keywords: Admixture; Durability; Freezing and Thawing; Mechanical properties; Lime mortar Polypropylene fibre 


\section{Introduction}

During the 20th century, cement mortars have been frequently used instead of lime mortars in restoration work, showing several incompatibilities: high mechanical strength, efflorescence phenomena owing to formation of large amounts of soluble salts by migration of alkaline ions, low water vapour permeability and higher thermal expansion coefficient than most masonry. [1-4]. Lately, there has been growing interest in using lime-based mortars for historical monument restoration [5, 6], as compatibility between the new repair mortar and the original components of the masonry is essential for the structure [7]. This compatibility must be reflected in several aspects: i) chemical compatibility between the applied mortar and the ancient stones, bricks and mortars; ii) physical compatibility, especially related to solubility and water transport; iii) structural and mechanical compatibility, reflected in similar mechanical strengths.

Within this framework, many different characteristics of lime pastes and lime-based mortars have been studied, such as fresh state properties [8], pore structure and capillary porosity [9], rheological behaviour [1, 10], mechanical behaviour in long-term studies, and durability [11-13].

However, some problems related to the use of aerial lime-based mortars still remain: i) long setting and hardening time; ii) relatively low mechanical strengths; iii) a high water absorption capacity through capillarity; iv) major volumetric change as a result of shrinkage [4]. This last drawback is usually accompanied by the development of cracks, which might give rise to aesthetic and functional consequences. 
In the field of cement-based mortars, fibre reinforcement has been suggested as one of the most effective methods to minimize plastic shrinkage and shrinkage cracking [14]. The use of different kind of fibre- natural products [15-17], manufactured admixtures [14, 18-21] and even metallic ones [22] - is widely accepted in cement mortars [21]. Several properties improve thanks to these additives: i) mechanical behaviour $[19,23]$; ii) volumetric changes such as shrinkage [18, 21, 22] and expansion [20], phenomena which lead to cracks [22]; iii) durability, especially in the face of freezing-thawing cycles [18]. The mechanism of action of these products seems to be related to their ability to act as a bridge between different grains of the cement mortar matrix, providing an additional surface where several components can crystallize [19]. At the same time, the uniformly distributed fibres reinforce the fresh mortar against the occurrence of plastic shrinkage and, once the hardened state has been reached, prevent microcracks from developing into macrocracks and the potential trouble which this may cause [21], such as a strength reduction, a water intake increase and a subsequent decay of the mortar by freezing-thawing cycles, and aesthetic involvements. This protection is possible because fibres can absorb the internal tensions generated in the structure [19].

Nevertheless, there is no previous research about the effect of fibres if they are incorporated into aerial lime-based mortars. As has been mentioned, mechanical strengths and shrinkage are some of the main problems associated with the use of lime mortars, so the addition of fibres could result in some interesting improvements for these materials. However, the hardening process and the final structure of lime mortar are very different from those of cement mortar, so a range of experiments has to be performed in order to determine whether the addition of fibres is appropriate for this binder. 
Polypropylene fibre has been shown to be one of the most suitable fibres for cement mortars [21], which could be due to its efficiency as well as to its great costeffectiveness [24]. In the present paper, the behaviour of aerial lime-based mortars modified with polypropylene fibres is reported. Drawing a parallel between cement and lime mortars, improvements in mechanical strength, volumetric changes and durability would be expected to be reached by introduction of polypropylene fibres. Fresh state properties, capillarity, water vapour permeability, mechanical strength over long-term studies as well as durability tests (freezing-thawing cycles) will allow us to draw conclusions about the improvement of aerial lime-based mortars.

\section{Materials}

An aerial commercial lime and a pure limestone aggregate were used to prepare the mortars. The lime (class CL 90-S according to Spanish standard [25]) was supplied by Calinsa (Navarra). The aggregate was supplied by Caleras de Liskar (grupo HORPASA), and was a calcareous type. Figures 1 and 2 present the mineralogical composition of the lime and aggregate used (obtained by X-ray diffraction) and their grain size distribution, respectively. The selected binder: aggregate ratio (B:Ag) was $1: 1$, by volume. This decision was taken according to previous data that showed the best mechanical strengths and durability performance in aerial and hydraulic lime mortars for this volumetric proportion $[5,26,27]$. Volume proportions were converted into weight in order to avoid any imprecise measurement. Three different dried mixtures were prepared. One of them was composed only of lime and aggregate, and was taken as a reference mortar. Fibre was incorporated into the other two mixtures aiming to test 
two very different percentages of fibre, in order to establish the fibre performance as a function of the dosage. The proven dosages were $0.06 \%$ and $0.5 \%$ of the total dried mortar's weight. The $0.06 \%$ dosage was selected because it is the dosage recommended in cement-based materials by the supplier (FOSROC). The $0.5 \%$ dosage is a very common ratio that has been reported in several previous works on the role of polypropylene fibre in cement mortars $[15,18,19,22,24]$. The polypropylene fibre used was obtained from a supplier as a commercial product: Fibrecrete 600, from FOSROC. The length of the thread was $6 \mathrm{~mm}$.

\section{Methods}

\subsection{Mortars preparation}

The amount of water was set in order to achieve a mortar slump of $160 \pm 10 \mathrm{~mm}$ after the flow table test. This value allows good workability while avoiding an excess of water which would be damaging for mechanical strengths, reducing them [5].

A Proeti ETI 26.0072 mixer was used. Lime, aggregate and fibre, if necessary, were blended for 90 seconds at low speed. Water was then added and mixed for 90 further seconds at low speed. Mortars settled for 10 minutes before being tested, to let the additive take effect. Straight afterwards, fresh state properties were determined as described below. Table 1 shows the composition of the three different mixtures.

\subsection{Rheological properties}


For the fresh state, consistency [28], density [29], air content [30], water-retention capacity (according to a previously described method [31], it was determined by weighing absorbent materials placed on the fresh sample before and after 5 minutes of contact under pressure) [32], setting time [33] and the visual effect of the mortars exposure at laboratory conditions when applied on brick surfaces were studied This last test consisted of spreading a $15 \mathrm{~mm}$ layer of mortar on a brick and observing any developments [31].

\subsection{Hardened state properties}

At hardened state, density, water absorption through capillarity [34], water vapour permeability [35], shrinkage [36], pore size distribution (by means of mercury intrusion porosimetry) and microstructure (using scanning electron microscopy with an EDS) were analysed. Furthermore, different test specimens were prepared in order to study mechanical strength at different ages (from 7 to 365 days). Durability was also studied through freezing-thawing cycles.

\subsubsection{Density and shrinkage}

The specimens used for the shrinkage and density at hardened state tests were those prepared for determining mechanical strength. Before the specimens were broken during the mechanical test, their length was measured with a gauge and the mass was set with a balance. Shrinkage coefficient was calculated according to the Spanish norm [36], measuring periodically the length variation of the specimens. 


\subsubsection{Pore structure}

Pore size distribution test was performed by using a Micromeritics AutoPore IV 9500 with a pressure range between 0 and $207 \mathrm{MPa}$. Pressure, pore diameter and intrusion volume were automatically registered.

\subsubsection{Mechanical strengths}

Mortars were moulded in prismatic 40x40x160 mm casts and demolded 5 days later [37]. Pastes were compacted in a specific device to remove excess of air bubbles and voids. Curing was performed in ambient laboratory conditions until the test day (RH 60 $\pm 10 \%$ and $20 \pm 5^{\circ} \mathrm{C}$ ). A total of fifteen specimens were prepared for each mixture; hence, 45 specimens were studied. Different curing ages were set: 7, 28, 91, 182 and 365 days; 3 specimens of each mortar were tested at each curing time, and the reported results are an average of all of them.

The three-point flexural tests were carried out in the mortar specimens using a Frank/Controls 81565 compression machine at low rates of loading $\left(10 \mathrm{~N} \cdot \mathrm{s}^{-1}\right)$. Flexural strength determination was done on the Ibertest IB 32-112V01. Compression strength tests were executed on the two fragments of each specimen resulted from the flexural tests. This was done on a Proeti ETI 26.0052, and the rate of loading was $50 \mathrm{~N} \mathrm{~s}^{-1}$.

\subsubsection{SEM examination}


Microstructure examination through scanning electron microscopy, using Philips XL 30CP Digital Scanning Microscope with EDS/EDAX Phoenix, was executed on different hardened mortars.

\subsubsection{Durability: Freezing-thawing cycles}

In order to test the efficiency of the polypropylene fibre, three different groups of specimens were prepared: a reference group, a mortar with low dosage of fibre and a mortar with high dosage of it. Mortars were prepared as aforementioned in 3.3.3. Curing was executed in ambient laboratory conditions over 56 days (RH $60 \pm 10 \%$ and $20 \pm$ $5^{\circ} \mathrm{C}$ ), and after that, samples were subjected to several freezing-thawing cycles. A total of six specimens were prepared for each mixture; hence, 18 specimens were studied. Different testing ages were set corresponding to 4,7 and 14 complete cycles. Weight exchange and qualitative alteration according to a previously proposed criterion were measured [11]. Two specimens of each mortar were tested at each time, and the reported results are an average of the two. Table 2 shows the characteristics of the set cycles.

\section{Results and discussion}

\subsection{Rheological properties}

\subsubsection{Amount of required water and consistency}

In the present study, the slump value was previously set, so Table 1 shows the amount of water that each mixture requires to achieve that value. When fibre was used at a low 
dosage, the amount of water needed was very similar to that for the reference material. However, when a higher amount of additive was incorporated, the amount of water required increased dramatically. Puertas et al. [18] reported that the addition of polypropylene fibres to cement mortars led to a reduction in workability and, therefore, a worse compaction of the material. This fact can be compared with the data obtained in the present study: as workability was previously set, the addition of fibres involved a rise in the amount of required water.

\subsubsection{Density}

As Table 3 shows, the more water was added, the lower density was achieved. In the present study, the largest amount of water used corresponded to a percentage of $24 \%$. Fernandes et al. reported that, for cement mortars, an increase in the kneading water implied a decrease in fresh density values up to a limit [38].

\subsubsection{Air content}

Only the addition of a large amount of fibre increased the air content of the mortar. The reported decrease in density can also be linked to this rise in the air content.

\subsubsection{Water-retention capacity}

This property was assumed not to change with the incorporation of the polypropylene fibre, so it was measured just to study any possible secondary effect. As Table 3 shows, 
water-retention capacity was large for all the mortars, as lime is a very retentive material [39]. The addition of fibres did not affect this property to a considerable extent.

\subsubsection{Setting time}

As was expected, this property depended directly on the amount of the incorporated kneading water. When a large amount of water was added, the paste remained fresh for longer, thus prolonging the setting time. This behaviour is due to the fact that lime mortars harden through two mechanisms: i) loss of excess water and subsequent compaction of the material and ii) carbonation process, which starts during the first steps of setting and can last several years. If the amount of kneading water is larger, the loss of its excess becomes slower, and also the excess of water prevents $\mathrm{CO}_{2}$ from gaining access to the mortar, thus slowing down the carbonation process. F-2 mortar showed an extraordinarily high value for setting time, in agreement with the huge amount of water that it required.

\subsubsection{Evolution on supports}

Figure 3 shows the appearance of the mortar's layers one day after their application on bricks. The selected bricks have a very high water-absorption coefficient in order to accelerate the evolution of mortars.

Although the water-retention capacity is very similar for the three mortars, their behaviour when applied on bricks was dramatically altered depending on the amount of fibre. The reference mortar showed a greater number of macroscopic cracks, produced 
because of the high water absorption coefficient of brick and plastic shrinkage of the mortar. When the additive was used at a low dosage, it managed to slightly reduce the number of cracks, while the largest dosage managed to eliminate the problem. This behaviour can be related to two different factors: i) the greater amount of kneading water incorporated during its preparation, which allows the mortar to keep enough water, preventing the formation of cracks in spite of the brick's absorption; ii) the influence of the fibre in the mortar matrix, reinforcing the structure [22].

\subsection{Hardened state properties}

\subsubsection{Density}

The addition of polypropylene fibres led to a reduction in the mass of the hardened mortar, which was an expected result [19] (Table 4 shows a density reduction: 1.67 g.mL ${ }^{-1}$ for the reference sample, while 1.63 and 1.54 for F-1 and F-2 samples, respectively). Garcia Santos et al. incorporated polypropylene fibres in cement mortars with the aim of reinforcing the composite material while reducing its weight. The larger amount of kneading water required by the modified mixtures produces a greater number of pores when it evaporates during the hardening process, which explains the decrease in density [5].

Figure 4 shows the percentages of weight loss experienced by the samples after the curing ages reported in section $3(7,28,91,182$ and 365 days) when they were dried in a heater at $100^{\circ} \mathrm{C}$ for 48 hours. The most remarkable point is that, as a result of their 
larger water content, F-2 mortars lost greater amounts of water and for longer periods of time than the rest of the specimens.

\subsubsection{Shrinkage}

As was expected for lime mortars, shrinkage coefficients were notable [40] (Table 4). Like lime-based mortars, the binding materials prepared with a large amount of kneading water - i.e. with water-absorbent components in their mixtures - undergo large shrinkage $[22,38]$.

In cement based materials, the polypropylene fibres have been proven to retard the first crack appearance and to reduce the inherent cracking tendency early in the life of the matrix, because at that early age the elastic modulus of the fibres is still higher than that of the binding matrix [14].

The very slight differences in length changes between the different mortars (values expressed as millimetres of variation per $1 \mathrm{~m}$ ) could be considered negligible. Therefore, in this first approach, polypropylene fibre seems not to be an effective product in order to improve this drawback of lime mortars, although it has shown to be suitable for cement mortars [18, 22]. However, Mesbah et al. [22] indicated that polypropylene fibre was more effective in controlling crack formation than in reducing the shrinkage. Actually, reduction in free shrinkage does not necessarily give indication of the overall reduction in the crack tendency [14]. In the present study, polypropylene fibres showed good behaviour in reducing the cracking tendency, although free shrinkage values failed to reflect this. 
Especially considering the F-2 sample, it has to be noticed that polypropylene fibres contributed to control the shrinkage produced by the excess of kneading water. The free shrinkage value for this sample turned out to be very similar to that of the reference mortar, even when the F-2 sample was prepared with $29 \%$ more kneading water (Table 1), so the fibre addition minimizes the shrinkage due to the excess of mixing water.

\subsubsection{Water absorption capacity through capillarity}

Water absorption is an extremely important property for mortars, as they are usually exposed to environmental phenomena - such as rain - or in contact with elements that could be wet. As a consequence, an inappropriate mortar could become damaged and cause water movement inside the building structure, thus affecting and damaging other materials such as stones, through efflorescence phenomena [9]. As Table 4 shows, the tested fibre hardly affects this characteristic of the lime mortars: the reference sample showed a capillarity coefficient of 2.36 , while 2.31 and 2.40 values were determined for F-1 and F-2 samples, respectively .

\subsubsection{Water vapour permeability - pore structure}

In the case of repair work, but also in single-coat applications, mortars should have an acceptable vapour permeability level, to allow water vapour to pass from the inside of the building to the outside and evaporate, avoiding water retention and condensation in the material, as well as reducing the transport of damaging ions in the pore structure [7, 41]. 
The diffusion coefficient expresses the difficulty that water vapour molecules find when trying to pass through a mortar, so the lower the coefficient, the higher the permeability.

As can be seen in Table 4, the diffusion coefficient was modified by the addition of polypropylene fibres. When a low dosage is incorporated, water vapour permeability decreases notably, whilst a higher amount of additive leads to an increase in this property.

The behaviour of F-2 mortar could be determined by its huge amount of kneading water which, as indicated in 4.2.1., evaporates during the hardening process giving rise to a large number of pores. These pores could be responsible for the water vapour permeability.

Figure 5 shows the obtained results for the hardened mortars. The reference mortar and F-1 sample showed a main peak - almost unimodal distribution - corresponding to $1 \mu \mathrm{m}$ diameter pores, which was in accordance with previous work on lime-based mortars [9, $27,42]$. The addition of a low dosage of polypropylene fibre led to a reduction in the percentage of the small peaks related to larger pores (diameters from $100 \mu \mathrm{m}$ to $10 \mu \mathrm{m}$ ) and to an increase in the volume of intruded mercury at the main peak. The reduction in the percentage of pores from $100 \mu \mathrm{m}$ to $10 \mu \mathrm{m}$ compared to the reference sample may be related to the lower water vapour permeability of F-1 sample. The mortar with larger amount of fibre also showed a main peak at $1 \mu \mathrm{m}$, which is also more intense than that for the reference mortar. F-2 mortar also presents an important group of peaks between 10 and $100 \mu \mathrm{m}$. Furthermore, all the mixtures containing fibre slightly shifted the main 
peak towards lower values: the larger the amount of fibre, the greater the displacement. These results indicate that the presence of polypropylene fibre at a low dosage contributed to block the larger pores and to fill to some extent the smaller ones, producing a more uniform pore size distribution characterized by a lower pore diameter. However, the high dosage of additive led to a distribution with larger amount of small pores - and with a lower diameter - than the reference material, but also to the appearance of a noticeable amount of larger pores.

The reason why F-2 showed such a different structure could be, as has been mentioned, the great amount of kneading water that it required which, after evaporating during the hardening process, gave rise to an outstanding number of large pores [5].

\subsubsection{Mechanical strengths}

Figure 6 shows the evolution of mechanical strengths over time. As can be observed, flexural and compressive strengths showed a similar behaviour. F-1 mortar followed an evolution similar to that for the reference mortar but improved during the last step. After 182 days of curing, plain lime mortar achieved its final strengths, while these properties continued increasing up to 365 days in mortar with a low amount of fibre (F-1). Final strengths were larger for the modified material. However, the highest dosage led to a reduction in final flexural and compressive strengths, which could be due to its large amount of kneading water and the subsequent increase in large pores.

Puertas et al. found that mechanical properties worsened with the incorporation of polypropylene fibres in cement mortars, and they related this behaviour to the fact that 
this additive gave rise to a less workable material whose compaction was, therefore, poorer [18]. As the achievement of a set workability was the criterion to prepare the mortars in the present study, this statement cannot be applied to the obtained data, and the large amount of incorporated water has to be pointed out as the main factor responsible for the observed behaviour. This fact is consistent with the conclusion of Lanas et al., who stated that an excess of water would result in a decrease in mechanical properties [5]. They also reported that discontinuities along the mortar structure would lead to a decrease in mechanical strengths. As the carbonation of portlandite yielding calcite is the only way of hardening in aerial lime mortars, the continuity of the formed calcite could be essential to achieve good mechanical behaviour. An excessively large amount of polypropylene fibres could therefore be affecting this continuity and preventing the material from generating a coherent matrix. A limit could thus exist for the fibre dosage in lime mortars which allows them to achieve desirable reinforcement without affecting the continuity of the matrix to a dangerous extent and without requiring an extremely high amount of kneading water which would be detrimental for the mortar's behaviour.

Taking into account the foregoing results, it could be suggested that there is a limit to the dosage of polypropylene fibre, after which the effect of this additive changes dramatically. As confirmed by pore structure assessments (section 4.2.4), the lowest used dosage of fibre produced only the aforementioned change in the matrix: reduction of the amount of larger pores and increase in the small ones. This led to a more compact material, thus explaining the lower water vapour permeability and the higher mechanical strengths. On the other hand, the highest amount of fibre produced a less compact mortar, which is in agreement with the lower density, the higher air content, 
the larger water vapour permeability and the lower mechanical strengths. Further research would be necessary to establish the best fibre dosage.

\subsubsection{SEM examination}

SEM examination showed the structure of the mortars with fibres (Figure 7). As can be seen in Figure 7.a), the polypropylene filaments seem to be isolated, not embedded into the matrix. More magnified images (Figs. 7.b) and 7.c)) showed that the fibres penetrated the material making holes in the lime matrix, but there was no deep interaction between calcite and filaments.

In the Introduction to the present study, several aspects of the action mechanism for these additives were reported. Taking into account the obtained images, the crystallization on fibre surfaces observed in cement mortars [19] seems not to take place in lime mortars. The reinforcement of the structure leading to a protection against crack formation may be occurring, as the evolution of mortars on supports indicates. This reinforcement may be due to the ability of fibres to absorb internal tensions, and to the fact that free space is created around the filaments, thus enabling their release. An excessively high amount of fibres would lead to a huge amount of void spaces and holes which, although it could be beneficial in avoiding cracking phenomena during shrinkage, are clearly detrimental for the final mechanical strengths.

\subsubsection{Durability: Freezing-thawing cycles}


Table 5 shows the alteration degree of the mortars after being subjected to several freezing-thawing cycles.

The reference material was completely destroyed after 6 freezing-thawing cycles (Figure 8), and it showed signs of deterioration from the first steps onwards. Mortar with fibres showed better behaviour than the reference material, especially when incorporated dosage was the highest one. This enhancement could be related to the ability of polypropylene fibres to absorb tensions, as explained in 4.2.6. The modified specimens absorbed more water than the reference samples from the first immersion in water onwards, which was reflected in their weight gain (Table 6). However, the presence of fibres and associated holes in the material allowed a distribution of the tensions generated during the thawing, leading to a more durable material in the face of these cycles.

\section{Conclusions}

A polypropylene fibre at two different dosages was tested as an additive to lime-based mortars, and various properties were studied in fresh state and also in hardened material, in order to test its efficiency.

When it was used at $0.06 \mathrm{wt} \%$, the mortar obtained was more compact than the reference material, thus leading to lower water vapour permeability and higher mechanical strengths. Furthermore, the number of cracks formed during shrinkage was lower and the durability of the material in the face of freezing-thawing cycles clearly improved. Therefore, the use of polypropylene fibre at relatively low dosages (as 
suggested by the supplier for cement-based materials) may be advantageous to improve mechanical strengths, durability in the face of freezing-thawing cycles and cracking in air lime-based mortars.

When fibre was incorporated at $0.5 \mathrm{wt} \%$, cracks were completely eliminated, but the mixture required such a great amount of kneading water in order to achieve a good workability that the resulting mortar had an outstanding number of large pores. At this large dosage, the addition of polypropylene fibre turned out to be detrimental to mechanical strengths and led to higher water vapour permeability. However, this addition improved durability (freezing-thawing cycles) and cracking.

Polypropylene fibre has been shown to be suitable in order to improve some properties of lime-based mortars, although there seems to be a limit to the dosage used from which its effect changes dramatically. This dosage may lie somewhere between the two studied, and further research would be needed in order to determine the ideal dose exactly.

\section{Acknowledgements}

The authors want to thank CTH Navarra and Fernando Moreno (Calinsa S.A. Navarra) for the material supplied. We are also grateful to Dr. Jon Joseba Echeberria for his help with SEM and to the staff in Laboratorio de Edificación (Universidad de Navarra) for the material support and invaluable help. This work has been funded by the Ministry of Education and Science of Spain (MAT2007-65478) and FUNA (Fundación Universitaria de Navarra). 


\section{References}

[1] Seabra MP, Paiva H, Labrincha JA, Ferreira VM. Admixtures effect on fresh state properties of aerial lime based mortars. Constr Build Mater 2009; 23:1147-1153.

[2] Rodríguez-Navarro C, Hansen E, Ginell WS. Calcium hydroxide crystal evolution upon aging of lime putty. J Am Ceram Soc 1998; 81:3032-3034.

[3] Veiga MR, Velosa A, Magalhaes A. Experimental applications of mortars with puzzolanic additions: characterization and performance evaluation. Constr Build Mater 2009; 23(1):318-327.

[4] Mosquera MJ, Silva B, Prieto B, Ruiz-Herrera E. Addition of cement to lime-based mortars: Effect on pore structure and vapor transport. Cem Concr Res 2006; 36:16351642.

[5] Lanas J, Alvarez JI. Masonry repair lime-based mortars: Factors affecting the mechanical behaviour. Cem Concr Res 2003; 33:1867-1876.

[6] Malinowski R. Ancient Mortars and Concretes, Durability Aspects. Mortars, Cements and Grouts Used in Conservation of Historic Buildings. Proceedings of the Symposium, ICCROM, Rome, 1981. p. 341-350.

[7] Mosquera MJ, Benitez D, Perry SH. Pore structure in mortars applied on restoration. Effect on properties relevant to decay of granite buildings. Cem Concr Res 2002; 32:1883-1888.

[8] Atzeni C, Farci A, Floris D, Meloni P. Effect of Aging on Rheological Properties of Lime Putty. J Am Ceram Soc 2004; 87(9):1764-1766.

[9] Arandigoyen M, Perez Bernal JL, Bello Lopez MA, Alvarez JI. Lime-pastes with different kneading water: Pore structure and capillary porosity. Appl Surf Sci 2005; 252:1449-1459.

[10] Seabra MP, Labrincha JA, Ferreira CM. Rheological behaviour of hydraulic limebased mortars. J Euro Ceram Soc 2007; 27:1735-1741.

[11] Lanas J, Sirera R, Alvarez JI. Study of the mechanical behavior of masonry repair lime-based mortars cured and exposed under different conditions. Cem Concr Res 2006; 36(5):961-970.

[12] Lawrence RM, Mays TJ, Rigby SP, Walker P, D'Ayala D. Effects of carbonation on the pore structure of non-hydraulic lime mortars. Cem Concr Res 2007; 37:10591069. 
[13] El-Turki A, Ball RJ, Allen GC. The influence of relative humidity on structural and chemical changes during carbonation of hydraulic lime. Cem Concr Res 2007; 37:12331240 .

[14] Toledo RD, Sanjuan MA. Effect of low modulus sisal and polypropylene fibre on the free and restrained shrinkage of mortars at early age. Cem Concr Res 1999; 29:1597-1604.

[15] Ramakrishna G, Sundararajan T. Impact strength of a few natural fibre reinforced cement mortar slabs: a comparative study. Cem Concr Compos 2005; 27:547-553.

[16] John VM, Cincotto MA, Sjostrom C, Agopyan V, Oliveira CTA. Durability of slag mortar reinforced with coconut fibre. Cem Concr Compos 2005; 27:565-574.

[17] Ramakrishna G, Sundararajan T. Studies on the durability of natural fibres and the effect of corroded fibres on the strength of mortar. Cem Concr Compos 2005; 27:575582.

[18] Puertas F, Amat T, Fernandez-Jimenez A, Vazquez T. Mechanical and durable behaviour of alkaline cement mortars reinforced with polypropylene fibres. Cem Concr Res 2003; 33:2031-2036.

[19] García Santos A, Rincón JM, Romero M, Talero R. Characterization of a polypropylene fibered cement composite using ESEM, FESEM and mechanical testing. Constr Build Mater 2005; 19:396-403.

[20] Park SB, Lee BC. Studies on expansion properties in mortar containing waste glass and fibers. Cem Concr Res 2004; 34:1145-1152.

[21] Song PS, Hwang S, Sheu BC. Strength properties of nylon-and polypropylenefiber-reinforced concretes. Cem Concr Res 2005; 35:1546-1550.

[22] Mesbah HA, Buyle-Bodin F. Efficiency of polypropylene and metallic fibres on control of shrinkage and cracking of recycled aggregate mortars. Constr Build Mater 1999; 13:439-447.

[23] Segre N, Tonella E, Joekes I. Evaluation of the stability of polypropylene fibers in environments aggressive to cement-based materials. Cem Concr Res 1998; 28:75-81.

[24] Boghossian E, Wegner LD. Use of flax fibres to reduce plastic shrinkage cracking in concrete. Cem Concr Compos 2008; 30:929-937.

[25] UNE-EN 459-1, Building lime. Part 1. Definition, specification and conformity criteria (2001).

[26] Lanas J, Perez Bernal JL, Bello MA, Alvarez JI. Mechanical properties of masonry repair dolomitic lime-based mortars. Cem Concr Res 2006; 36(5):951-960. 
[27] Lanas J, Perez Bernal JL, Bello MA, Alvarez JI. Mechanical properties of natural hydraulic lime-based mortars. Cem Concr Res 2004; 34(12):2191-2201.

[28] UNE-EN1015-3, Methods of test for mortar for masonry. Part 3: Determination of consistence of fresh mortar (by flow table) (2000).

[29] UNE-EN 1015-6, Methods of test for mortar for masonry. Part 6: Determination of bulk density of fresh mortar (1999).

[30] UNE-EN 1015-7, Methods of test for mortar for masonry. Part 7: Determination of air content of fresh mortar (1999).

[31] Izaguirre, A, Lanas J, Alvarez JI. Effect of water-repellent admixtures on the behaviour of aerial lime-based mortars. Cem Concr Res 2009; 39(11):1095-1104.

[32] UNE 83-816-93, Test methods. Mortars. Fresh mortars. Determination of water retentivity (1993).

[33] UNE-EN 1015-9, Methods of test for mortar for masonry. Part 9: Determination of workable life and correction time of fresh mortar (2000).

[34] UNE-EN 1015-18, Methods of test for mortar for masonry. Part 18: Determination of water absorption coefficient due to capillary action of hardened mortar (2003).

[35] UNE-EN 1015-19, Methods of test for mortar for masonry. Part 19: Determination of water vapour permeability of hardened rendering and plastering mortars (1999).

[36] UNE 80-112-89, Test methods. Cement. Determination of shrinkage and swelling in water (1989).

[37] UNE-EN 1015-11, Methods of test for mortar for masonry. Part 11: Determination of flexural and compressive strength of hardened mortar (2000).

[38] Fernandes V, Silva L, Ferreira VM, Labrincha JA. Influence of the kneading water content in the behaviour of single-coat mortars. Cem Concr Res 2005; 35:1900-1908.

[39] Green KM, Carter MA, Hoff WD, Wilson MA. The effects of lime and admixtures on the water-retaining properties of cement mortars. Cem Concr Res 1999; 29:17431747.

[40] Collins FG, Sanjayan JG. Workability and mechanical properties of alkali activated slag concrete. Cem Concr Res 1999; 29:455-458.

[41] Maravelaki-Kalaitzaki P. Hydraulic lime mortars with siloxane for waterproofing historic masonry. Cem Concr Res 2007; 37:283-290.

[42] Collet F, Bart M, Serres L, Miriel J. Porous structure and water vapour sorption of hemp-based materials. Constr Build Mater 2008; 22:1271-1280. 


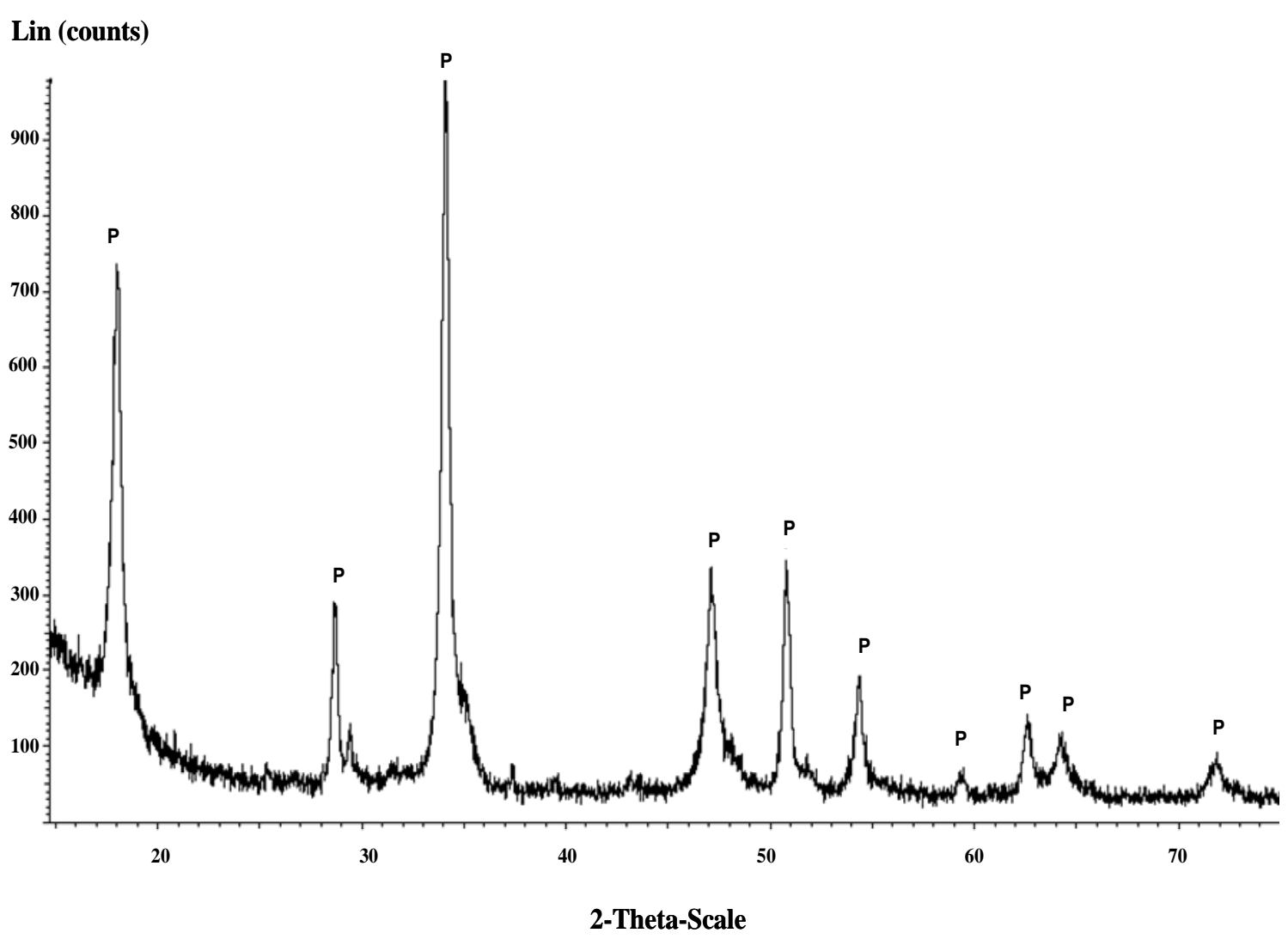

a)

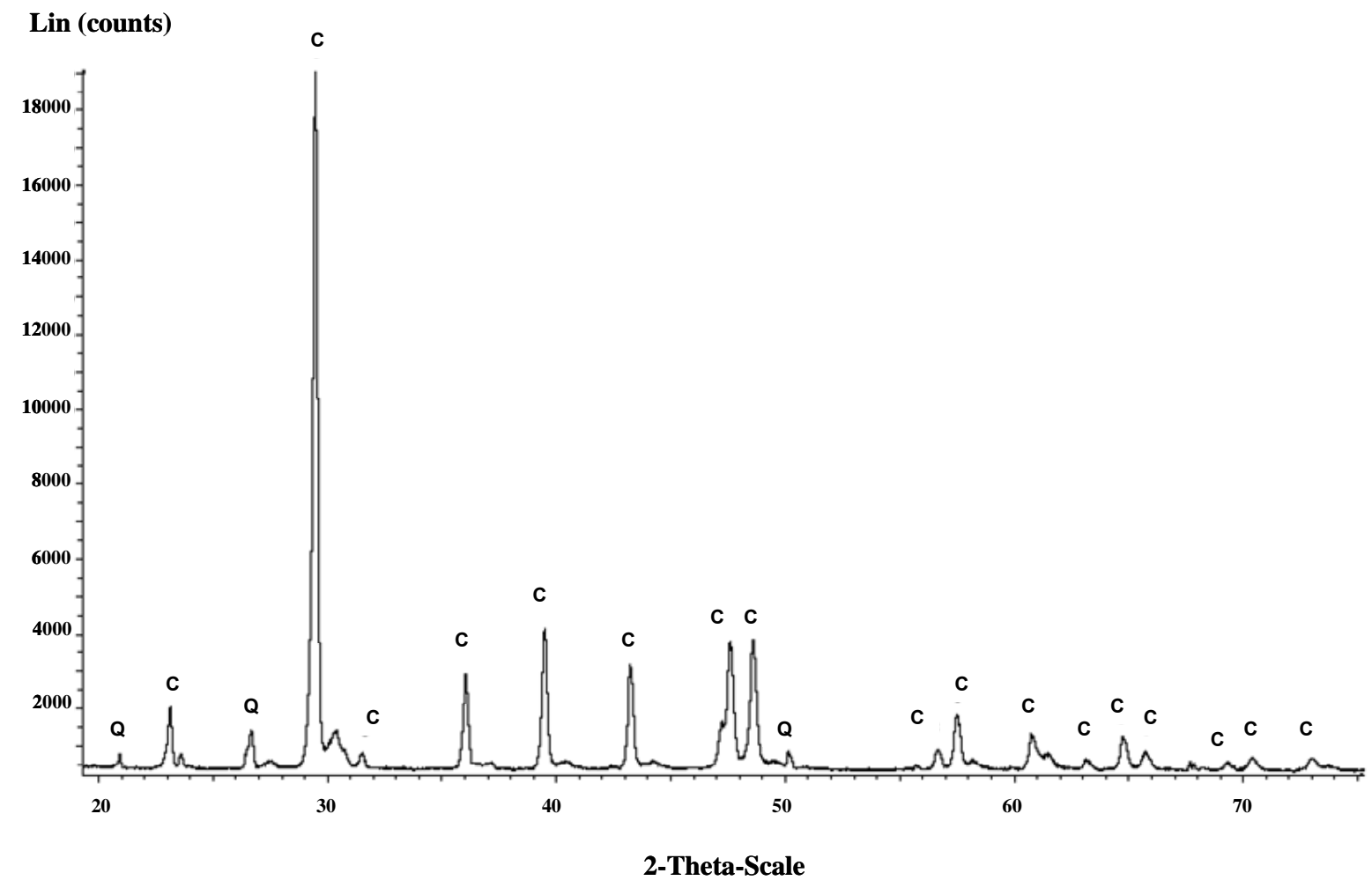

b)

Figure 1. XRD patterns for a) lime and b) aggregate, where P: portlandite; C: calcite;

Q: quartz. 


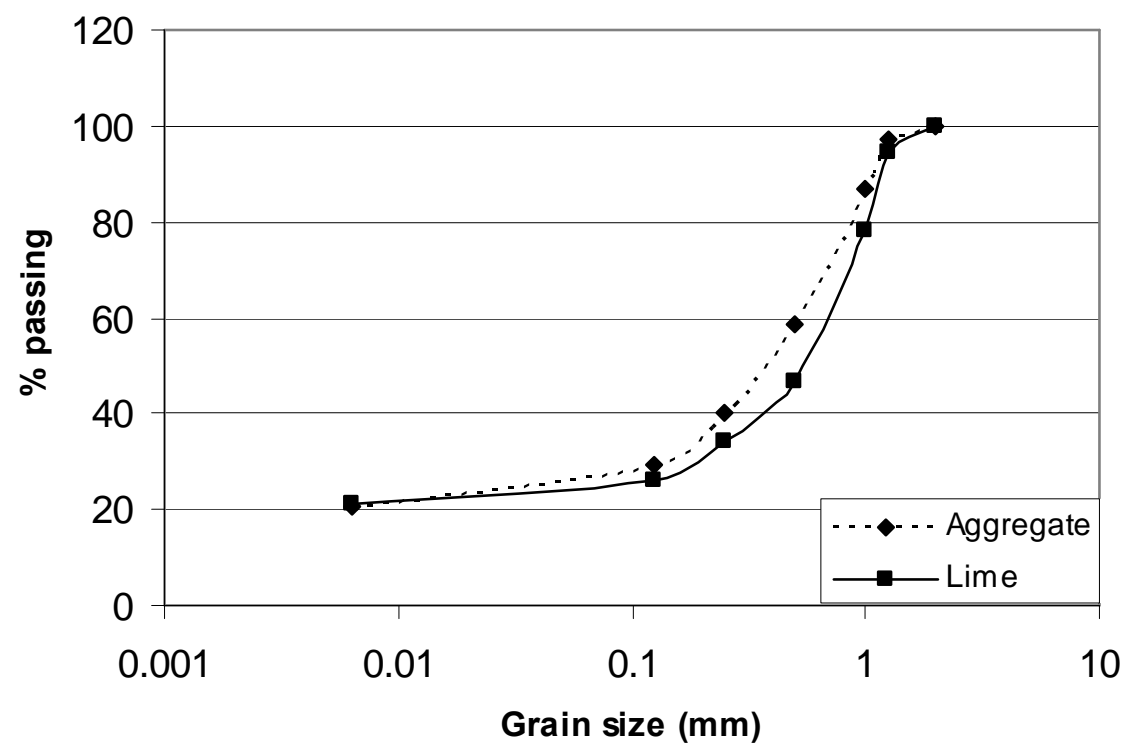

Figure 2. Grain size distribution of lime and aggregate.
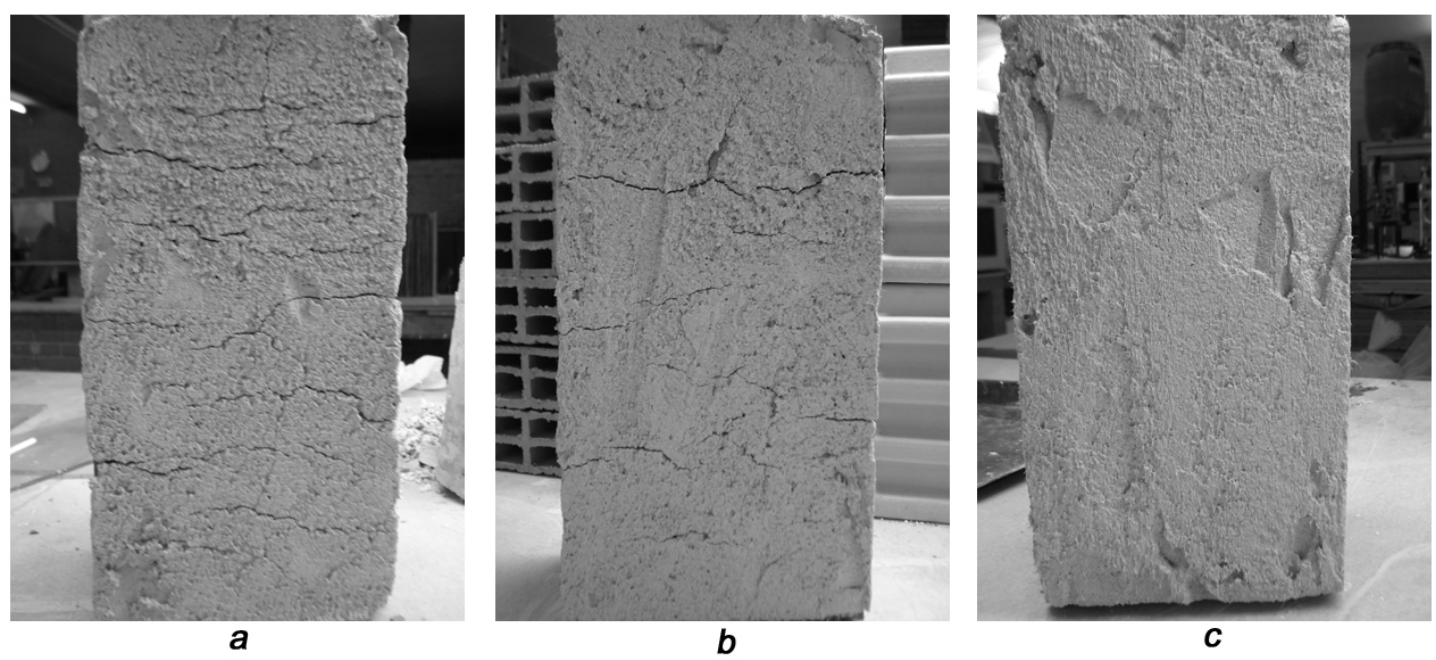

Figure 3. Evolution of mortars on bricks. a) REF; b) F-1; c) F-2. 


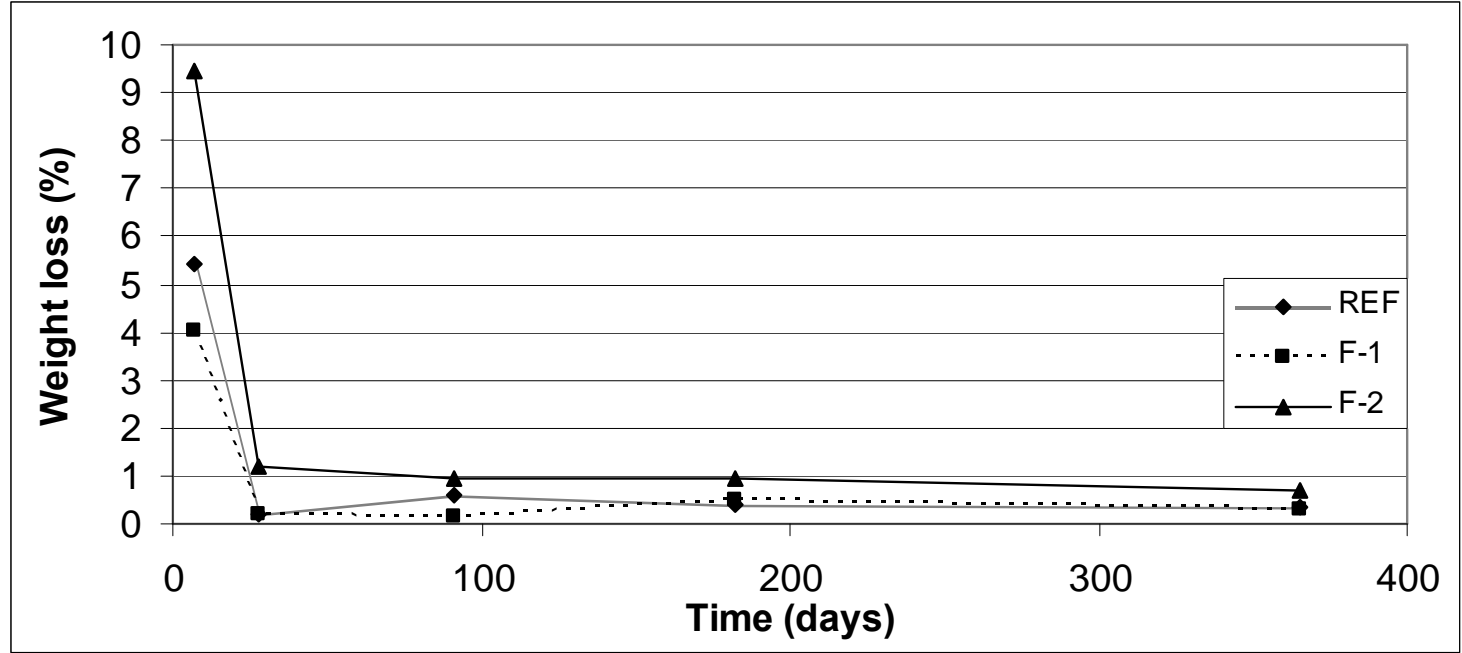

Figure 4. Weight loss (\%) of mortars during drying at 7, 28, 91, 182 and 365 curing days. 


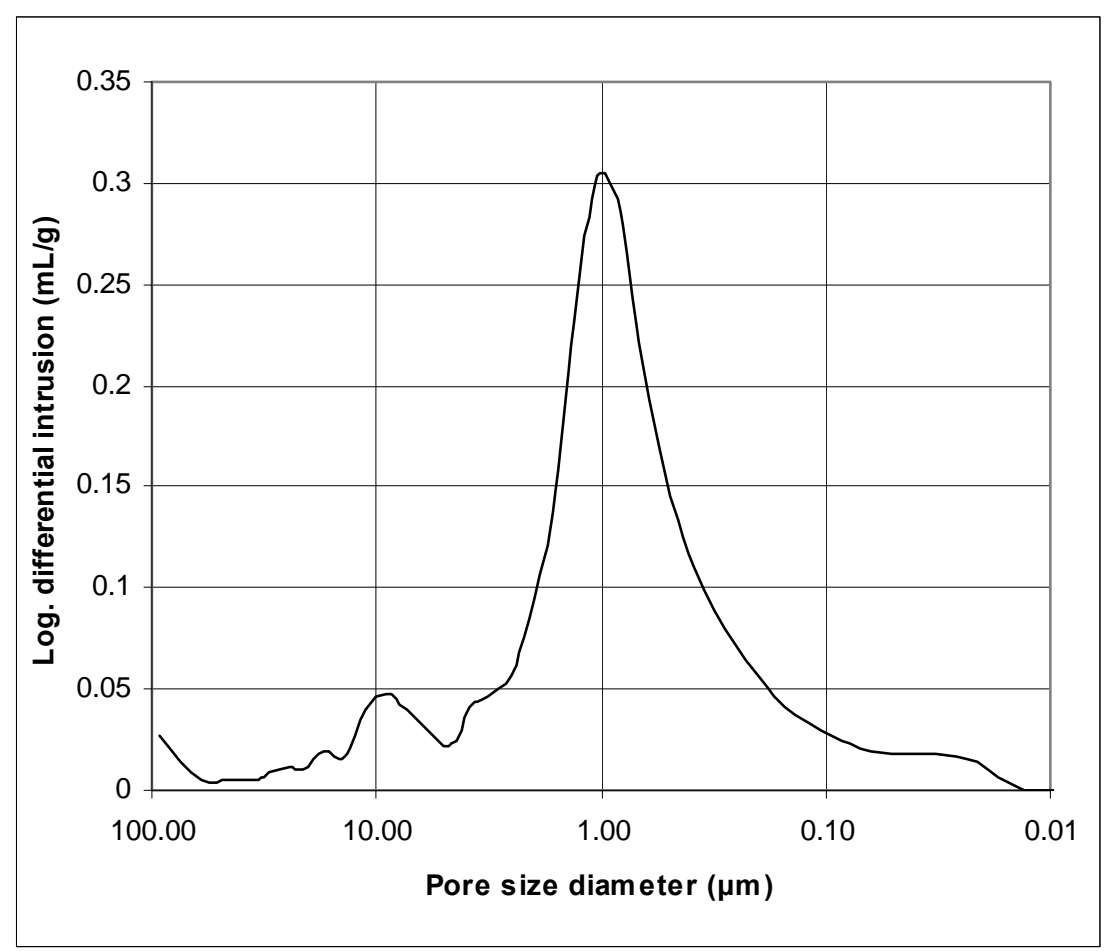

a)

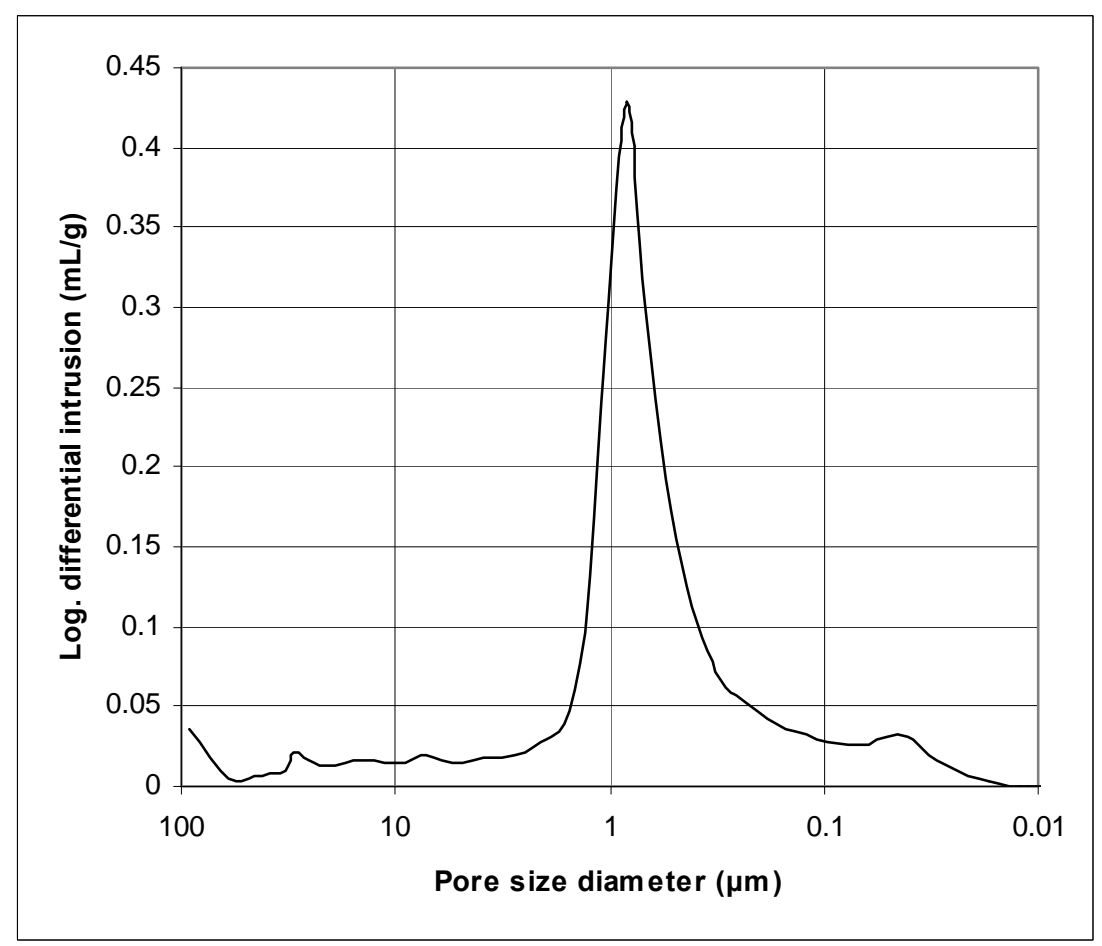

b) 


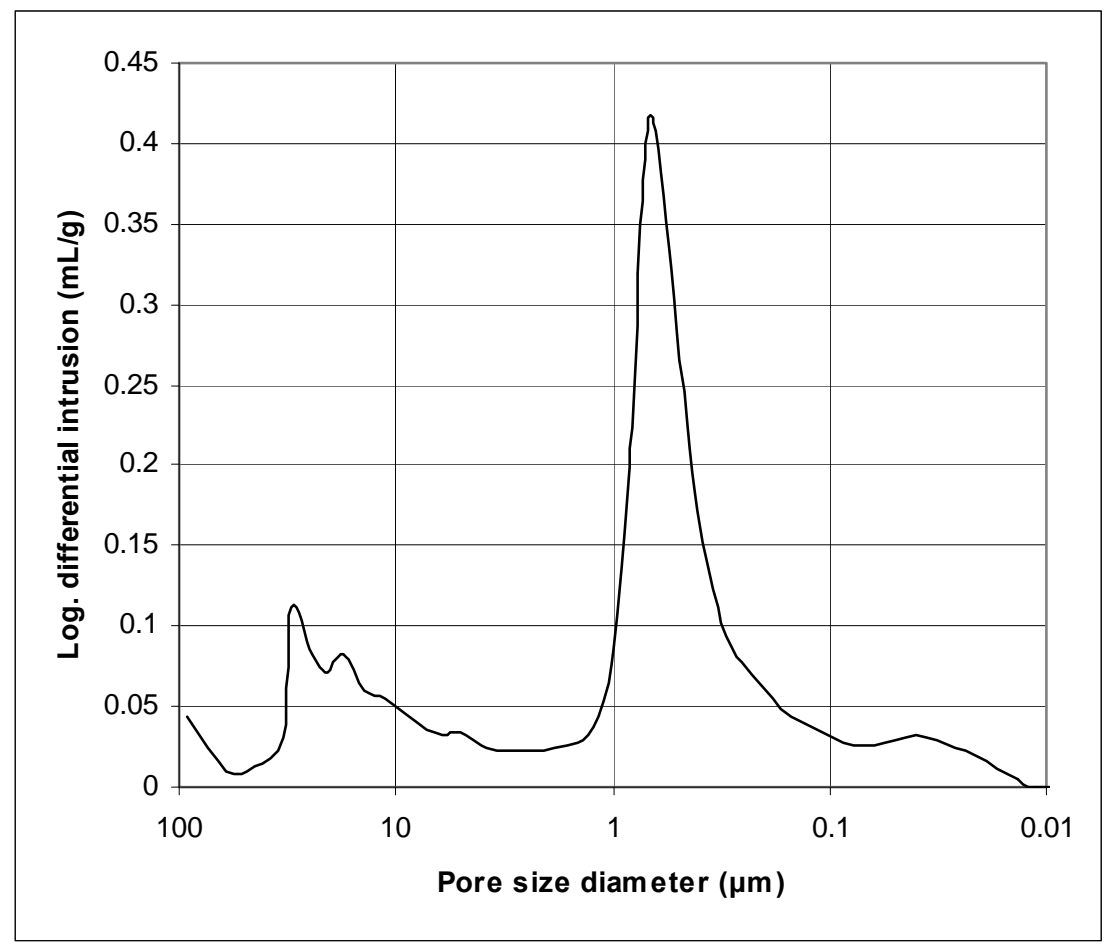

c)

Figure 5. Results from mercury intrusion porosimetry for the studied mortars; a) REF; b) F-1; c) F-2. 


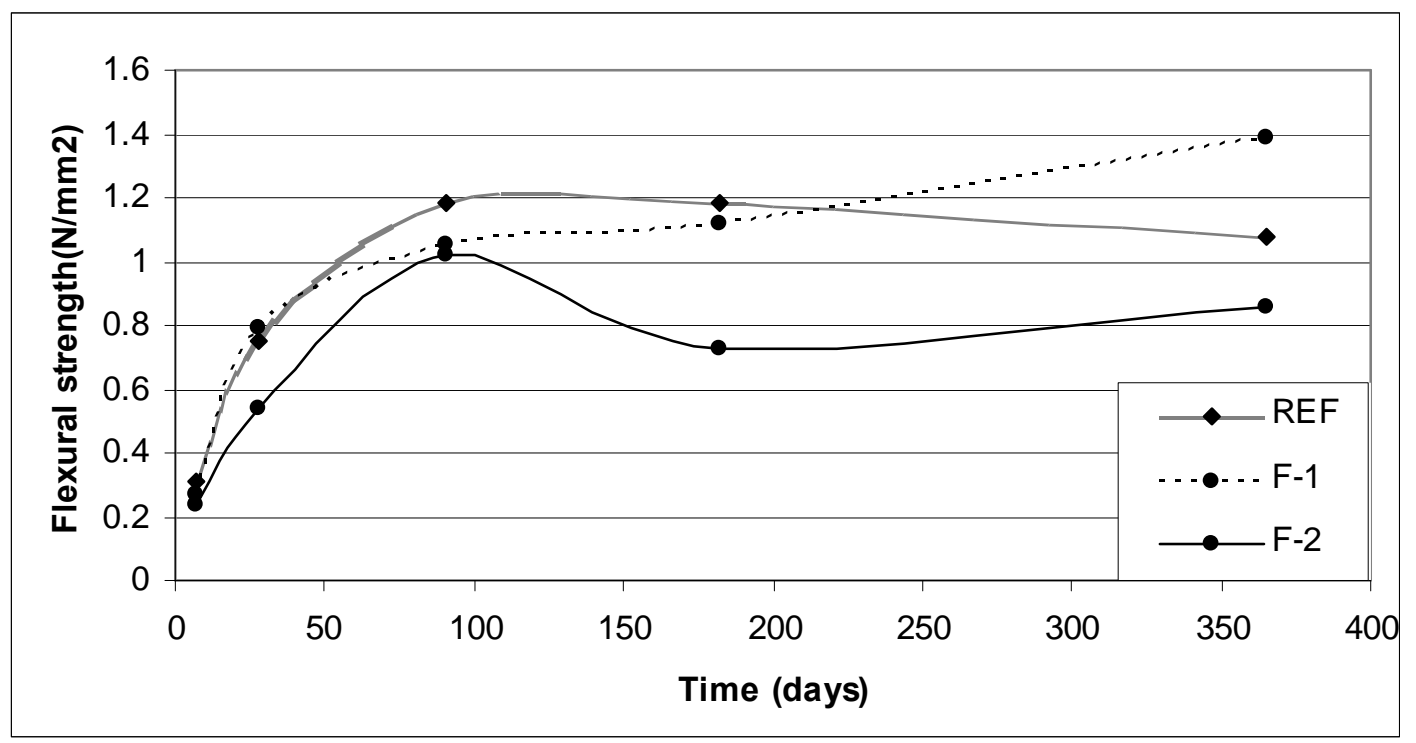

a)

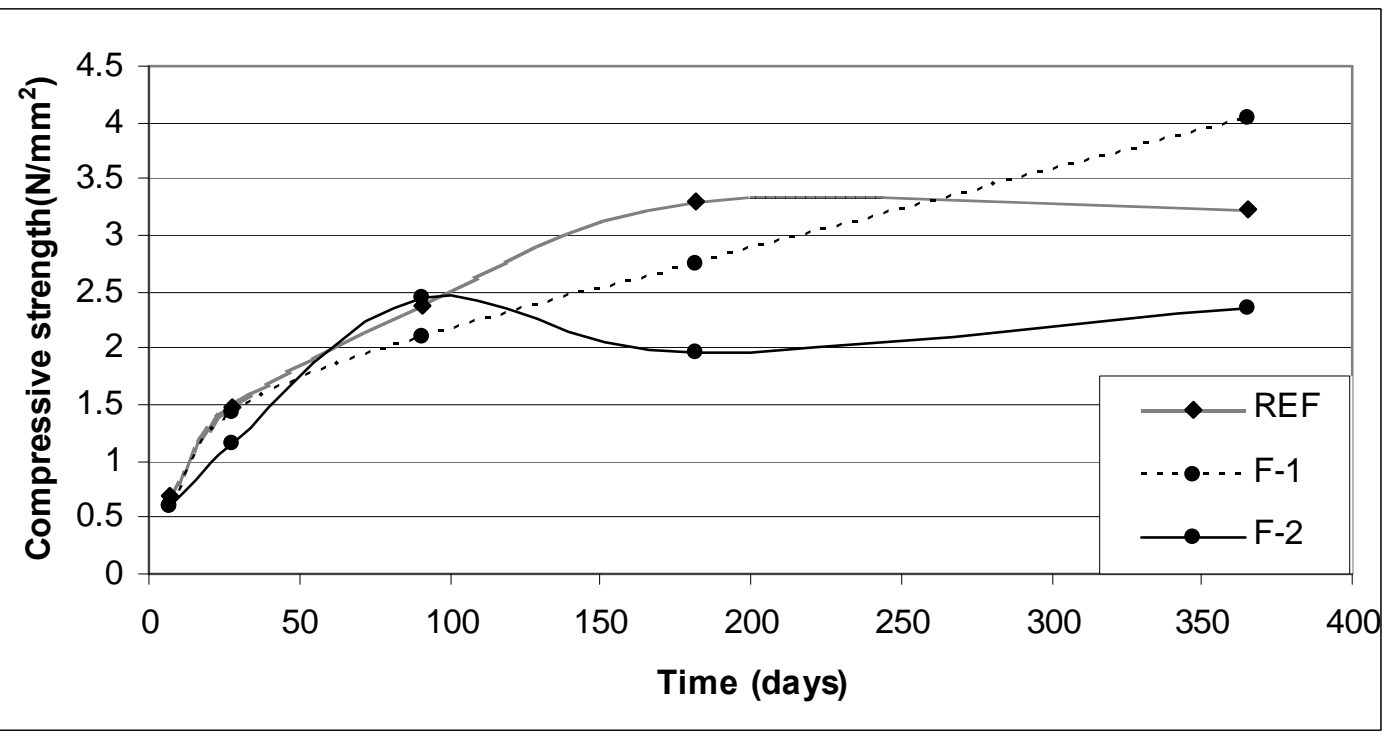

b)

Figure 6. Flexural and compressive strength vs. time for the tested mortars. 


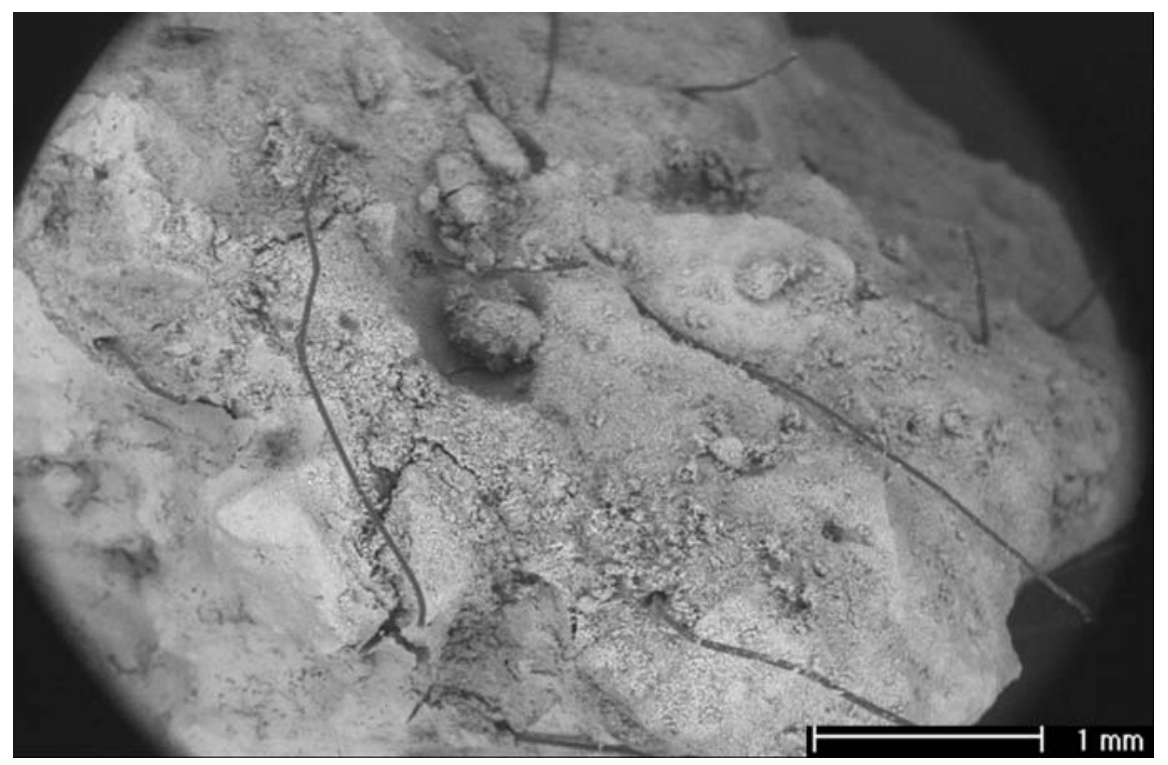

a)

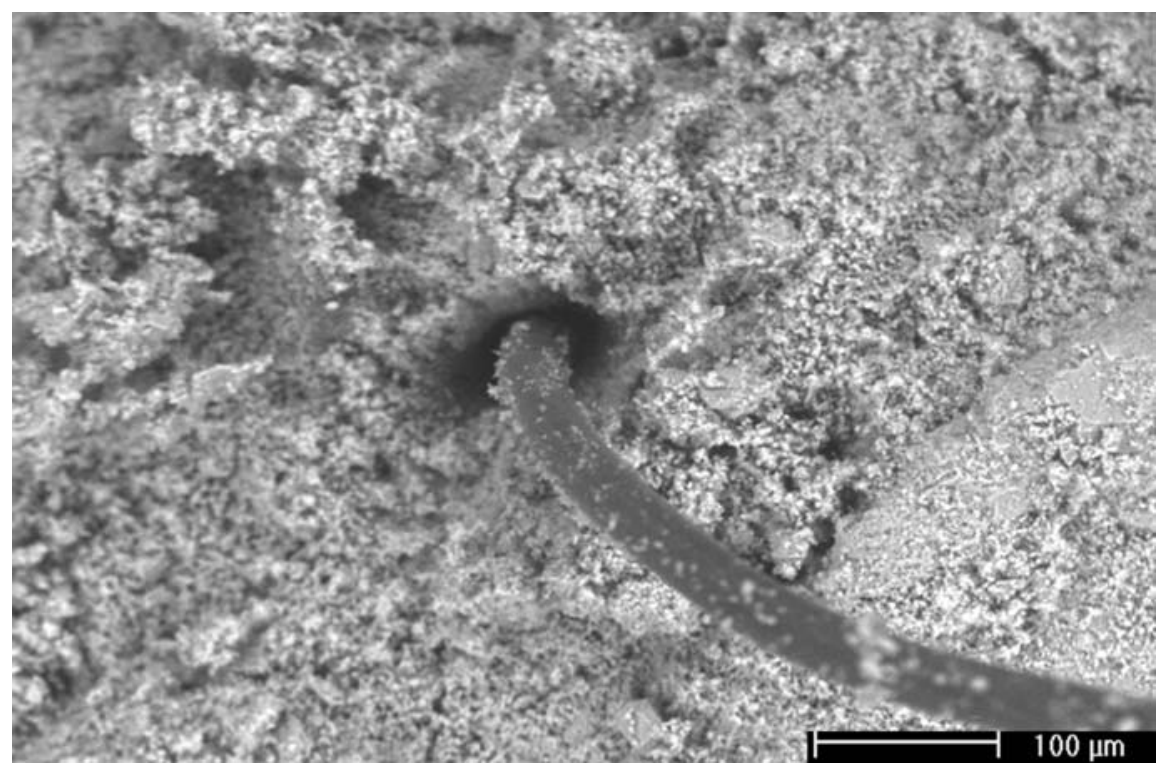

b) 


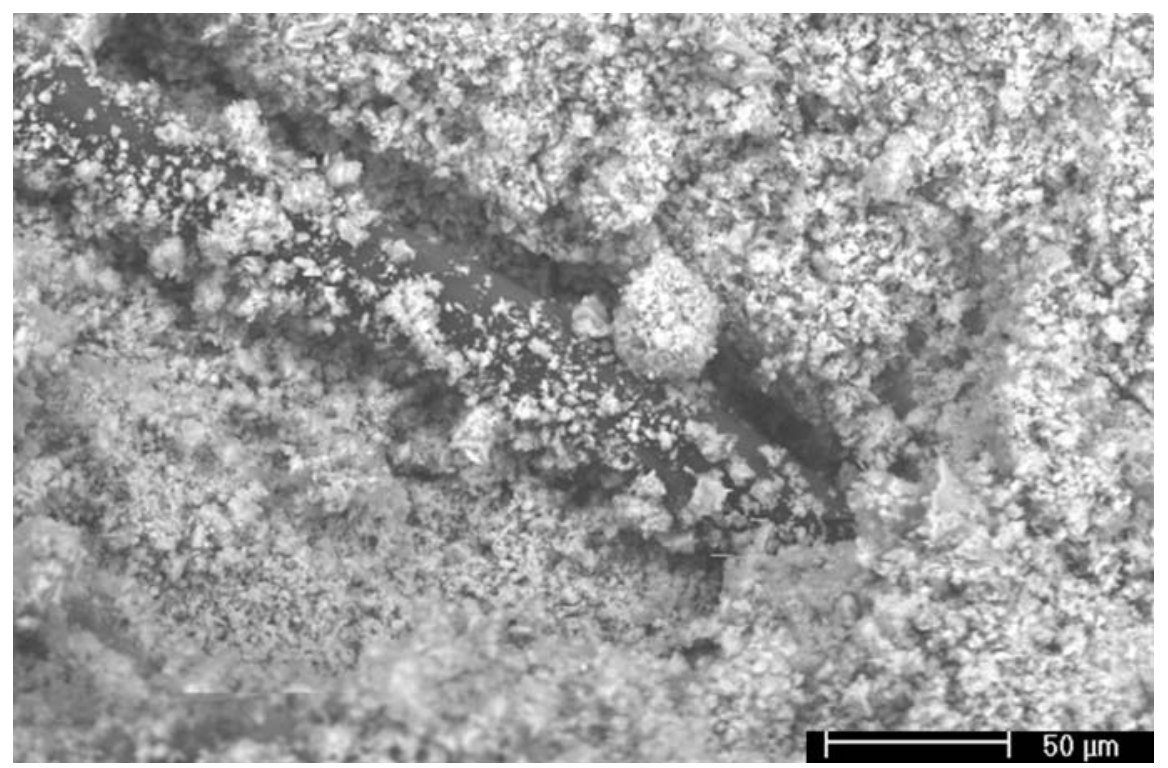

c)

Figure 7. SEM images obtained from the mortars with fibre.

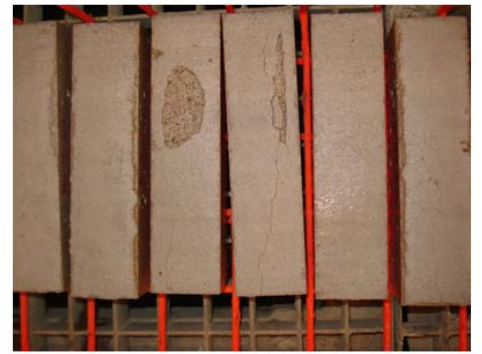

a
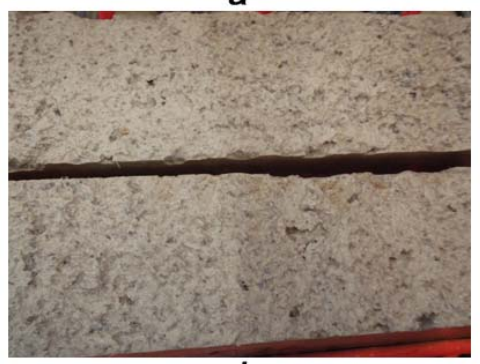

$d$

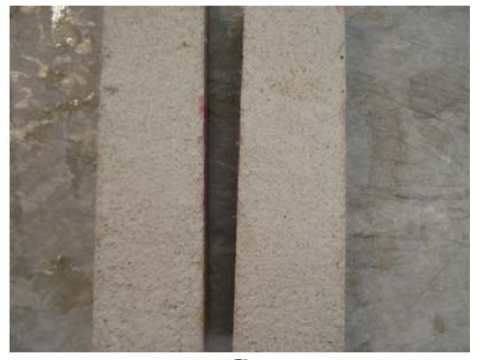

$g$

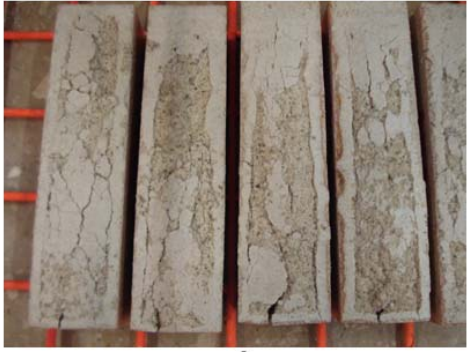

b

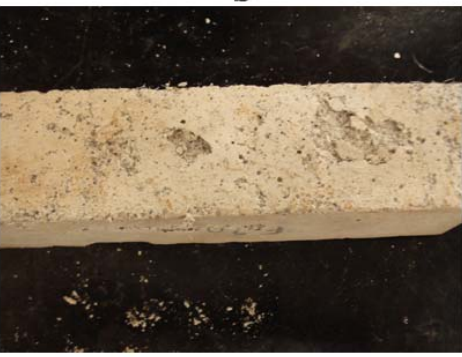

e

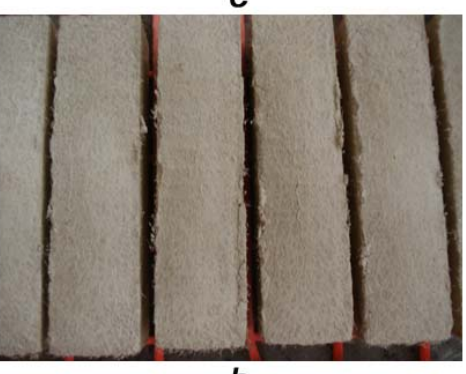

$h$

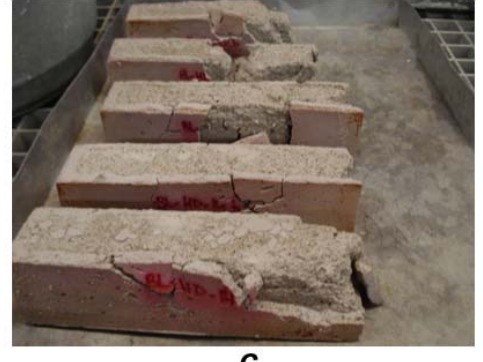

C
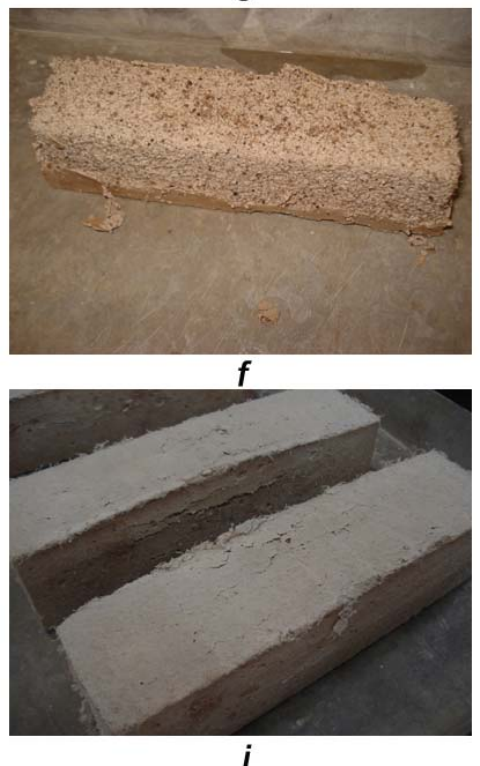

Figure 8: a) Tested specimens after freezing-thawing cycles; a) REF samples after 1 cycle; b) REF samples after 4 cycles, with evidences of alteration; c) REF samples after 6 cycles, totally destroyed; d) F-

1 specimens after 4 cycles; e) F-1 mortar after 7 cycles; f) F-1 specimen after 14 cycles showing high degree of deterioration; g) F-2 samples after 4 cycles; h) F-2 mortars after 7 cycles, with slight signs of deterioration; i) F-2 samples after 14 cycles, with high degree of alteration. 